\title{
An economic and environmental total life cycle costing methodology and a web-based tool for environmental planning of buildings
}

\author{
S. M. Haddad, F. Haghighat \& S. Alkass \\ Building, Civil and Environmental Engineering, Concordia University, \\ Montréal, Canada
}

\begin{abstract}
This research is a translation of the international Kyoto protocol into practical steps towards effective environmental planning in the building industry. This research develops a methodology to quantify environmental impacts of building materials to be used along with standard life cycle costing evaluation (LCC) resulting in total life cycle costing (TLCC).

Based on the developed methodology, the economic LCC of building materials is calculated according to the ASTM's standard methodology, while their environmental impact is first quantified in tones of $\mathrm{CO}_{2}$, based on Global Warming Potential (GWP), and then translated into monetary value to be used in the environmental impact LCC. Quantification of studied materials emission is done with the help of "SimaPro", a professional life cycle assessment tool, considering their total life span. Monetary value of quantified $\mathrm{CO}_{2}$ emission is then taken from actual $\mathrm{CO}_{2}$ stock markets (i.e. Point Carbon: www.pointcarbon.com). Total life cycle costing (TLCC) is then calculated from both the estimated economic and the environmental impact LCCs.

The methodology aims at a number of building professionals: 1) designers, 2) material specification writers and quantity surveyor, 3) permit authorities, 4) research groups, 5) developers, and 6) manufacturers. The methodology is supported with a web-based design tool named "EconoEnviroTLCC Tool". The tool's main goal is to put the developed methodology into practice by building professionals to better plan to achieve sustainable buildings. The tool enables its users to evaluate LCC, environmental LCC and total life cycle costing (TLCC) of partial and/or complete building envelope elements. The tool's results are presented in tabular and graphic formats.

Keywords: life cycle costing, environmental impact, building materials, building envelope, environmental design support tool.
\end{abstract}




\section{Introduction}

A joint study by the World Resource Institute and other international organizations [9] shows that Global energy use has risen by nearly $70 \%$ since 1971 (an average of $2 \%$ per year) and is poised to continue its steady increase over the next decades. In the building industry area, for example, the residential sector alone is responsible for $27 \%$ of the total world's energy consumption. The International Energy Agency (IEA) projects that global energy consumption and annual $\mathrm{CO}_{2}$ emissions - have risen by almost 50\% from 1993 levels. This has great impact on our globe and our life as a result. Over the last few years, many national and international organizations have focused on issues related to Sustainable Built Environment. Many methodologies and tools, at different scales and localities, have been developed. Such tools play a very import role in promoting sustainability in the building industry [5]. The international community has come together, represented by delegates of most countries, to put a strategy to limit the human sufferings from the human negative influence on the environment.

The Kyoto protocol, a landmark on the path of saving the environment in December 1997 [7], has defined clearer roles for participating countries with more specific environmental pollution figures and deadlines that participants have to abide with. In order to promote sustainable development, some protocol articles indicated that each participating country shall implement policies and measures in accordance with its national circumstances.

The protocol states that participating parties shall, individually or jointly, ensure that their aggregate anthropogenic carbon dioxide equivalent emissions of the greenhouse gases do not exceed their assigned amounts, with a view to reducing their overall emissions of such gases by at least 5\% below the 1990 levels in the commitment period 2008 to 2012.

Life cycle costing LCC, the method used to "Justify a certain expenditure on a project/system by proving its savings along its life span" [1], has proven its viability in many fields, including the building industry. This research develops a methodology to evaluate total life cycle costing (TLCC) (both economic and environmental) of building materials. The mythology utilises the ASTM LCC principles on the economic evaluation and the Kyoto concept of emission trading on the environmental evaluation.

\section{Economic life cycle costing and environmental impact life cycle costing}

In the building industry, LCC is a straight forward method of comparing, projects, buildings or systems, old or new, to determine the lowest LCC amongst several alternatives. It is a very strong tool to justify higher initial costs to prove reduction along the total life span [10]. Such reduction could not be visible unless costs such as operation, maintenance, replacement and/or environmental savings are included. 
The method utilizes a technique that sums all relevant costs over a designated period of time, assumed to be the expected life span. When applied on buildings, in their design, renovation or even demolition stage, LCC could take into account some or all related costs such as: property, design, material, systems and equipment, construction or demolition, operation \& maintenance and disposing of all involved elements. The summation could be in either present-value (PV) or annual value (AV) terms and takes into account discount and inflation rates. Several figures that are used in LCC calculations have to be actual costs (i.e. material costs) and could be taken directly from market or supplier prices or from pricing reference manuals such as RSMeans. On the other hand, some assumptions, during the calculation process, have to be made for other included elements such as maintenance costs, period of study, tax rate, inflation rate, nominal and/or real discount rates, initial and salvage monetary value of evaluated items $[1,6]$.

The basic calculation of LCC of a project (building or system) in present value terms (PVLCC) could be expressed in the following equation (1) and graphically represented as shown in figure 1.

$$
L C C^{P V}=\sum_{t=0}^{N} \frac{C_{t}}{(1+i)^{t}}
$$

where:

$$
\begin{array}{ll}
\mathrm{C}_{\mathrm{t}} & =\text { sum of all relevant costs occurring in year } \mathrm{t}, \\
\mathrm{N} & =\text { length of study period in years, and } \\
\mathrm{i} & =\text { discount rate. }
\end{array}
$$

The above equation represents the summation of several equations that apply for life cycle of each building material separately; the process that is used in this research and applied in the developed EconoEnviroTLCC Tool and represented in the equation (2) [1] below.

where:

$$
\mathrm{PVLCC}=\mathrm{IC}+\mathrm{PVM}+\mathrm{PVR}+\mathrm{PVF}-\mathrm{PVS}
$$

$$
\begin{aligned}
& \mathrm{IC}=\text { initial cost } \\
& \mathrm{PVM}=\text { present value of maintenance and repairs cost } \\
& \mathrm{PVR}=\text { present value of replacements cost } \\
& \mathrm{PVF}=\text { present value of fuel and energy cost } \\
& \mathrm{PVS}=\text { present value of re-sale or salvage-value. }
\end{aligned}
$$

On the other hand, life cycle costing of environmental impact of building materials is hard to comprehensively evaluate. A basic concept for evaluating environmental damage, of any material or activity, depends mainly on the balance between needs and benefit to stakeholders and end users. In other words, it depends on how much benefit and damage it does to its community in general. This is based on the concept of "social willingness to pay" to remove material/component and/or minimize the damage caused by the emissions from these materials or activities (Figure 2). This concept stays meaningless unless it is translated to measurable means such as: finding the costs adhered to removing and/or preventing the emissions of a material or activity from the environment. 


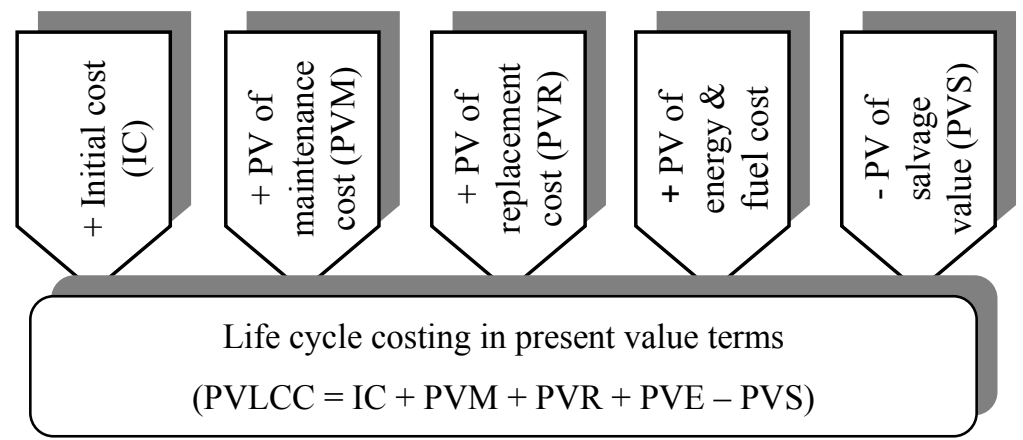

Figure 1: Calculation process of life cycle costing in present value terms.

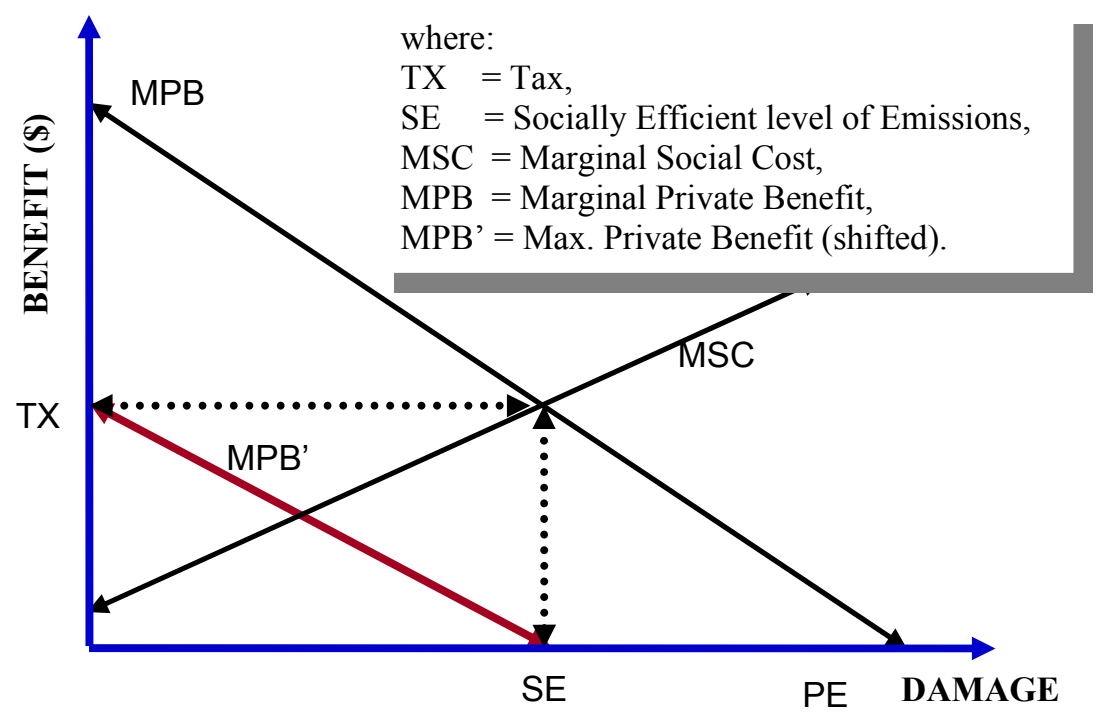

Figure 2: Benefit-damage balancing of a building.

Assigning monetary values for environmental impact of materials/systems is a science that is still in its very early stages. There are few trials in this direction, among which the EIO-LCA [3], and the Building for Environmental and Economic Sustainability tool [2]. However, the subject of this research is to develop a total life cycle costing for buildings and building materials that account for their direct costs and the cost related to their environmental impact. The research develops a methodology and a design support tool that could be easily and successfully used by building designers and/or officials to develop several alternatives for partial and/or complete buildings to choose the most economic and environmental friendly building material based on LCC principles. 
The monetary evaluation of environmental impact, the main subject of this study, is based on the concept of: "Cost adhered to prevent an environmental damage, or cost applied to remove it" [4]. This research develops a methodology that applies this concept and abides with the Kyoto protocol articles to establish monetary evaluation methodologies of the environmental impact of buildings and building materials. The protocol states that "some participating parties shall, individually or jointly, ensure that their aggregate anthropogenic carbon dioxide equivalent emissions of the greenhouse gases do not exceed their assigned amounts . . . etc. This concept of is translated into emission trading strategy; between countries (and companies as well) that have committed themselves to an emission ceiling as per the Kyoto protocol agreement" [7].

Any environmental impact monetary evaluation could be simply based on the concept of cost related to preventing or removing related impact(s), as mentioned above. Emerging from this concept, this research considers and applies costs adhered to removing the damage caused by $\mathrm{CO}_{2}$ in its monetary evaluation of environmental impact of building materials. $\mathrm{CO}_{2}$ emissions of building materials is simulated and quantified using an life cycle analysis tool (SimaPro) and then its monetary value is defined according the $\mathrm{CO}_{2}$ current market value that is accessible form $\mathrm{CO}_{2}$ market trading (i.e. www.pointcarbon.com).

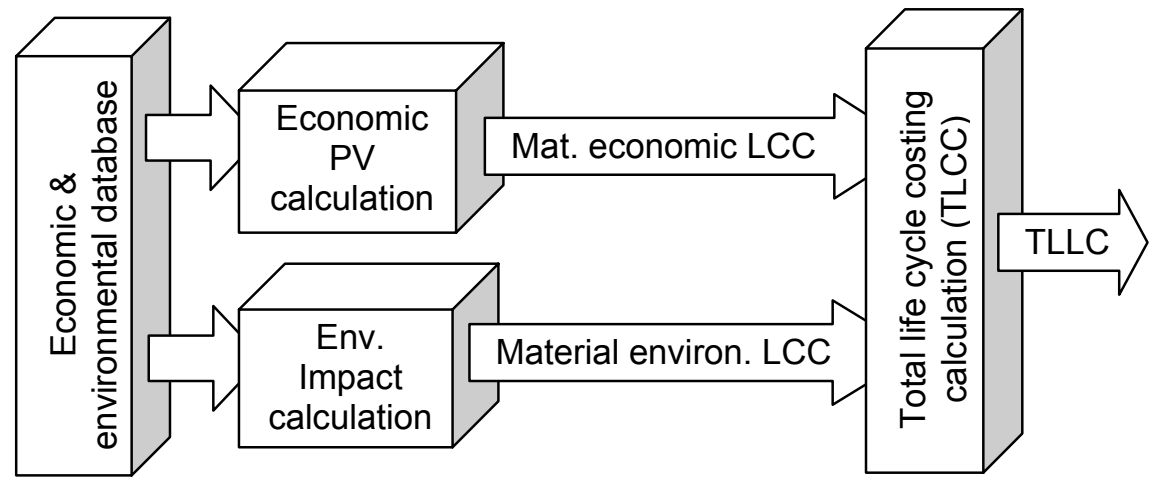

Figure 3: Economic and environmental total life cycle costing (TLCC) calculation process.

\section{Total life cycle costing (TLCC) methodology}

The Total Life Cycle costing (TLCC) that accounts for direct cost and the cost of environmental impact of building materials, are calculated as per the procedure highlighted below (figure 3):

a. Calculate economic life cycle costing in present value terms "PVLCC" (as shown above). 
b. Calculate environmental impact life cycle costing "EILCC" (as explained above).

c. The sum of both PVLCC and EILCC is the anticipated total life cycle costing (TLCC), as represented in the equation below. TLCC $=$ PVLCC + EILCC

where:

$$
\begin{aligned}
& \text { TLCC = total life cycle costing of building envelope materials } \\
& \text { (in Dollars), } \\
& \text { PVLCC }=\text { economic life cycle costing (Dollars in present value } \\
& \text { terms), and } \\
& \text { EILCC = environmental impact cost of building materials (in } \\
& \text { Dollars). }
\end{aligned}
$$

\section{The EconoEnviroTLCC Tool}

Beyond the developed methodology, as shown above, a design support tool, named the "EconoEnviroTLCC Tool" has been designed aiming at building designers and professionals to expand the methodology and put it forward for practice. The evaluation of the available sustainable tools showed that designers are still in-need for a total life cycle costing tool that integrates between economic and environmental costs buildings and building materials resulting in a total life cycle costing evaluation [5]. Even though that there are some trials in this regard, however, none of the available tools achieved as much features as those of the EconoEnviroTLCC Tool. Above all, none has been as straight forward towards buildings and building designers/professionals as the EconoEnviroTLCC Tool. The EconoEnviroTLCC consists of several input and output modules:

- Introductory module,

- Project module,

- Material module (economic and environmental data),

- Economic LCC module,

- Environmental LCC module,

- Graphics module,

- Administrator's module, and

- Help module.

Using the EconoEnviroTLCC Tool could be summarised in the following step:

Inputs steps where a user can:

- Start with creating a new project where he/she can define project's location, year, discount rate, $\mathrm{CO}_{2}$ market price (per tone) and currency of the evaluation (figure 4).

- Select building envelope elements (i.e. roofs, walls, doors, ... etc.) and define their quantities (i.e. $\mathrm{m}^{3}$ or $\mathrm{m}^{2}$ ). 


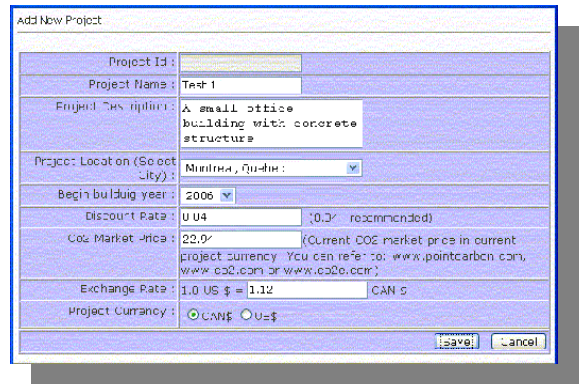

Figure 4: Creating a new project.

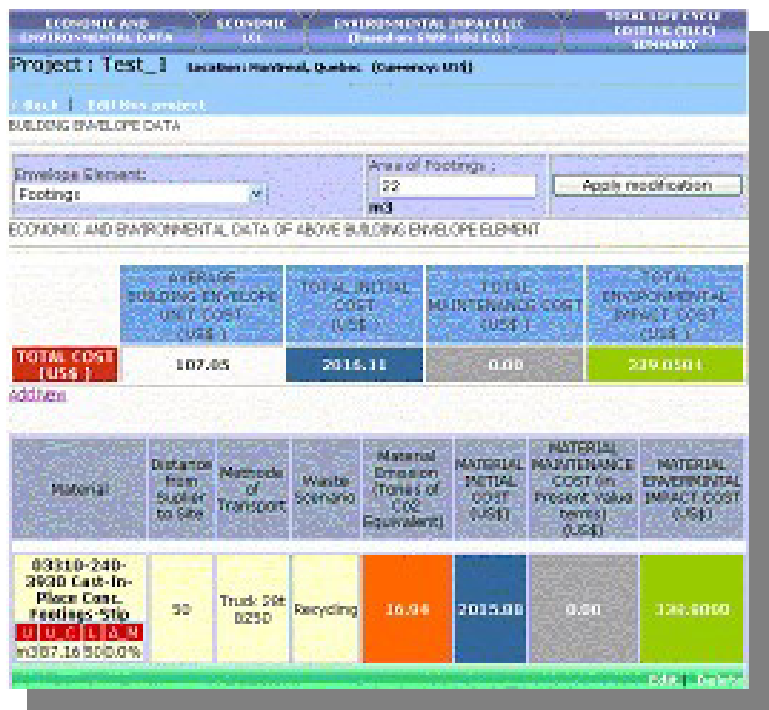

Figure 5: $\quad$ Selecting building envelope elements and building materials.

- Select materials for each envelope element where for each selected material, a user can use default values or override them with his/her own values. These values include economic and environmental values such as: material unit price, life span, annual maintenance cost, salvage value, distance material to be brought to construction site, method of transportation and end of life scenario. All above mentioned elements affect the economic and environmental life cycle calculation; therefore, uses are advised to be careful about values they use (figure 5).

- Economic life cycle costing in present value terms (PVLCC) of selected materials could be seen separately (for each building envelope element) or combined for the project as a whole (figure 6).

- Environmental impact life cycle costing (EILCC) of selected materials could be seen separately (for each building envelope element) or combined for the project as a whole (figure 7). 


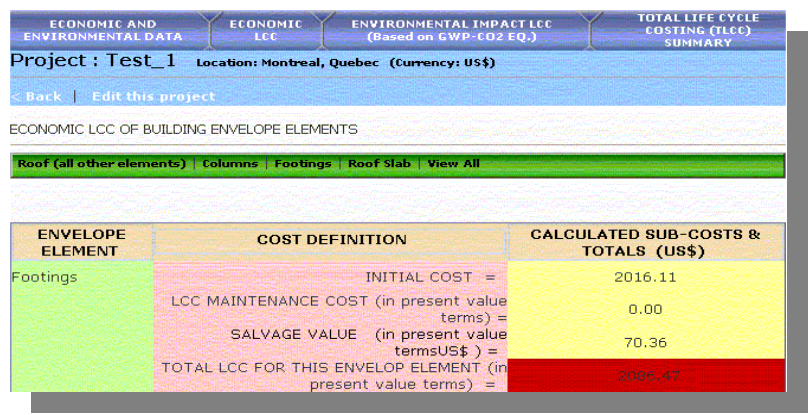

Figure 6: Economic LCC results.

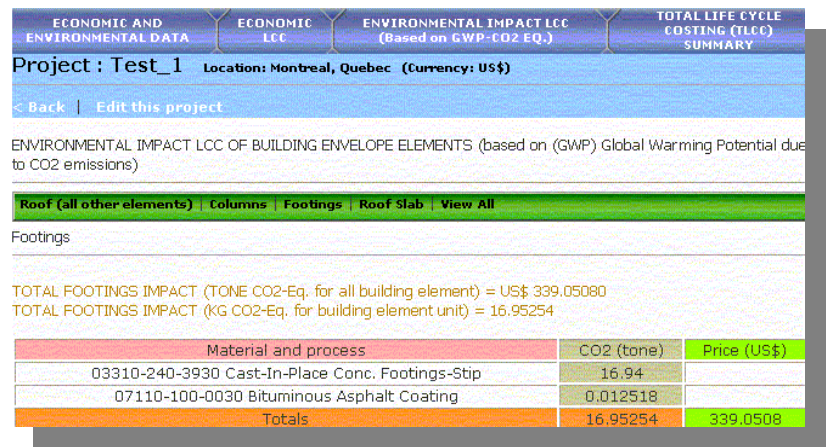

Figure 7: Environmental LCC results.

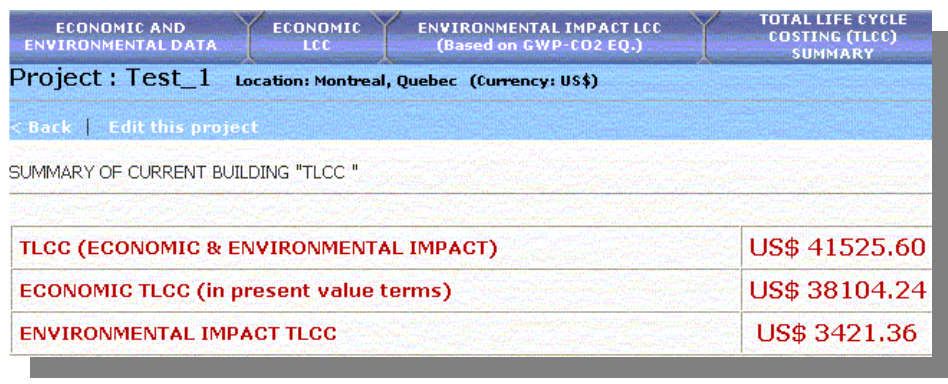

Figure 8: Total life cycle costing (TLCC) results.

- Total life cycle costing (TLCC) of the whole project could be seen in a separate screen showing both economic and environmental totals (figure 8).

- Bar graphic presentation of a single project that compares between its economic and environmental LCC could be presented, printed or saved to file. 


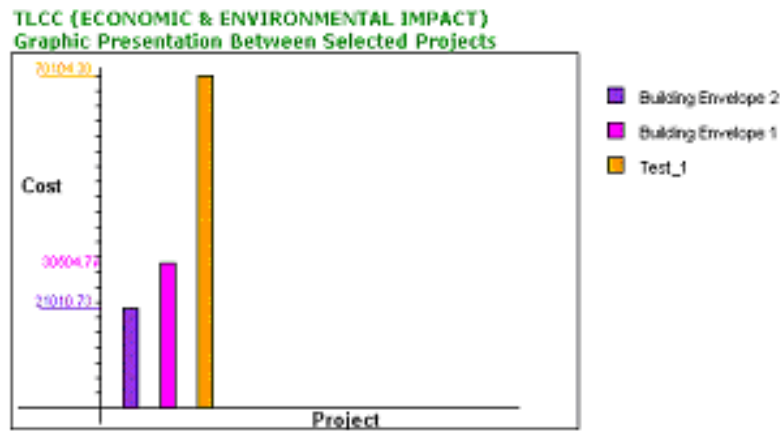

Figure 9: Project-to-project comparison in graphic presentation.

- Bar graphic comparison could be selected to compare between several projects comparing between their TLCC, economic PVLCC and environmental EILCC in three separate graphs (figure 9).

- Help menu could be accessed at any time to assist users on how to use the tool.

\section{Conclusion}

The building industry, which has a large consequence on resource depletion and energy consumption, results in large negative environmental effects. Governmental, private and public organisations have worked throughout the last few years to save our environments. Their efforts resulted in developing strategies, treaties, methodologies and environmental tools. All role players in the building industry (i.e. owners, designers, manufacturers and authorities) carry a share of the responsibility in this regard. Building designers, where the starting point of building realization takes place, could be the most important players in the process. The developed methodology in this research equips building designers as well as other building professionals with the proper tool (the EconoEnviroTLCC Tool) to plan for environmentally friendly designs.

The developed methodology where environmental impact of buildings and building materials are evaluated in monetary terms based on LCC standards opens the way to its acceptance internationally, where every one understands it.

This research is a step, among the early ones, in the direction of evaluating the environmental impact. The outcome of this research helps not only to expand the understanding of environmental impact of building materials to all related individuals and groups, but also to increase the possibility of environmentally friendly building design planning and achievement.

\section{References}

[1] ASTM, E 917 - 99 (2000), Annual Book of ASTM Standards, Pennsylvania, United States. 
[2] BEES $^{\mathrm{R}}$ (2003), National Institute of Standards and Technology, Building and Fire Research Laboratory, Computer program and user manual, V3.0d, May 2003.

[3] Carnegie Mellon University Green Design Institute. (2006), Economic Input-Output Life Cycle Assessment (EIO-LCA) model, official website http://www.eiolca.net (2006).

[4] Goedkoop, M. and Spriensma, R. (2001), Third Edition, Eco-Indicator 99 methodology report, PRé Consultants (June 2001), Amersfoort, the Netherlands.

[5] Haddad, S., Alkass, S. and Haghighat, F. (2003), "Sustainable Building Design and Assessment Tolls, Current evaluation and future Expectations"; Proceedings of the $31^{\text {st }}$ Annual Conference of the Canadian Society for Civil Engineering, pp. END-250, June 4-7 June, Moncton, New Brunswick, Canada.

[6] Kirk, S. J. and Dell'lasola, A. J. (1995), Life Cycle Costing for Design Professionals, Second Edition, McGraw-Hill, Inc., New York.

[7] UNFCCC (1998), Kyoto Protocol to the United Nations Framework Convention on Climate Change (UNFCCC website, (http:/unfccc.int/resource/docs/convkp/kpeng.html).

[8] World Resource Institute (1998), Power Surge: Energy use and emissions continue to rise, A joint publication by the White, J., Case, K., Pratt, D., and Agee M. (1998), Principles of Engineering Economic Analysis, Fourth Edition, John Wiley \& Sons, Inc., New York.

[9] World Resources Institute, the United Nations Environment Programme, the United Nations Development Programme, and the World Bank.

[10] Zhang, K. (1998), Life Cycle Costing for Office Buildings in Canada, M.SC. Thesis, Department of Building Engineering, Concordia University (Supervisor, Dr. S. Alkass). 